\title{
Research on Collaborative Design Method for Apparel Mass Customization in the Internet Plus Era
}

\author{
Zhang Ying, Li Li, Xing Xue \\ Fashion, Art and Design Institute, Donghua University, Shanghai, China \\ Email address: \\ aimee_zy@outlook.com (Zhang Ying),winnerlili@126.com(Li Li),xingxue1990@126.com (Xing Xue)
}

\section{To cite this article:}

Zhang Ying, Li Li, Xing Xue. Research on Collaborative Design Method for Apparel Mass Customization in the Internet Plus Era. International Journal of Economics, Finance and Management Sciences. Vol. 4, No. 6, 2016, pp. 369-377. doi: 10.11648/j.ijefm.20160406.19

Received: November 10, 2016; Accepted: November 30, 2016; Published: December 5, 2016

\begin{abstract}
The growing accessibility of internet service, especially in the Internet Plus era, supported mass customization in the apparel industry. As mass customization emphasize on providing individually-designed products and services to meet every customer requirement, the advanced Internet-based service systems help achieve high process flexibility and integration. In this paper, we studied the triangle relations among consumer, brands' designer, and manufacturer in collaborative design process in apparel mass-customized product development. As well as explained the advanced technologies enabling collaborative design process, such as toolkits for co-design, 3D body scanning, and CAD systems. We finally gave three feasible recommendations for apparel industry to apply mass customization strategy.
\end{abstract}

Keywords: Internet Plus, Apparel Mass Customization, Collaborative Design, Customer Co-design

\section{Introduction}

As China's economy matures, China's State Council has unveiled a ten-year national plan, Made in China 2025, which is designed to transform and upgrade China from a manufacturing giant into a world manufacturing power [33]. This initiative draws direct inspiration from "Industry 4.0"

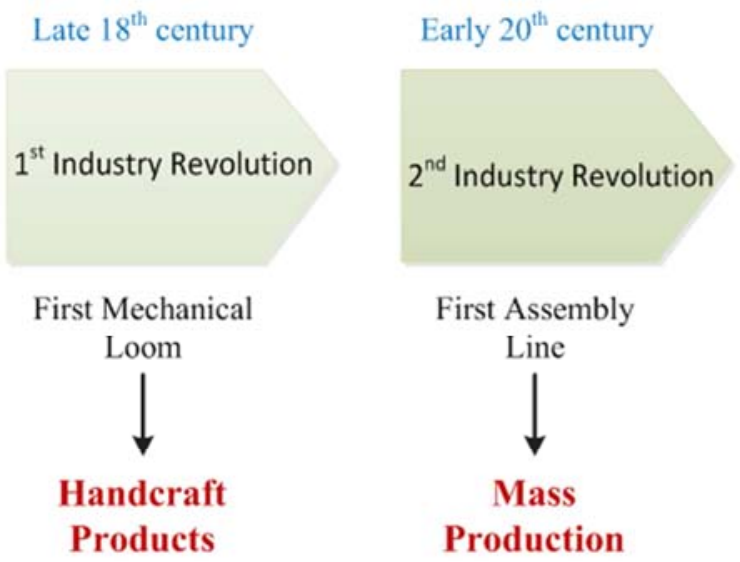

plan, which was initially discussed in 2011 and later adopted in 2013 by German government. Based on "Made in China 2025", Chinese Prime Minister Li Keqiang released national strategy of "Internet Plus", aiming to integrate internet service (e.g. mobile Internet, cloud computing, big data, and the Internet of Things) with traditional transaction, to accelerate the development of smart manufacturing [34].

Early 1970 s $21^{\text {th }}$ century

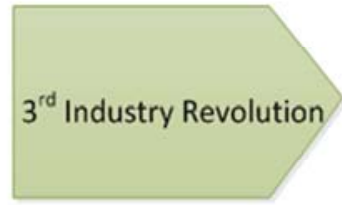

First Programmable logic Controller<smiles>C1C[Te]1</smiles>

Computer-aided

Manufacturing
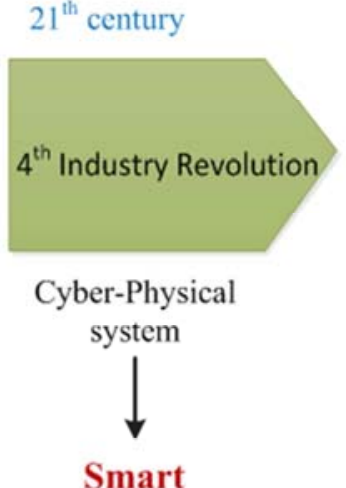

Manufacturing

Fig. 1. How the four industry revolution influence apparel industry.

With the help of Internet service, traditional garment industry is currently varying from homogenized low-cost product competition to customized and high-qualified product competition. As illustrated in Fig. 1. Along with this 
trend, the apparel mass customization emerged, making a tremendous transformation from traditional mass production. Mass customization is a win-win strategy for both production and distribution, combined the advantages of fully customized and mass production. To be specific, it not only meets customer demands, but also makes the business keep relatively low production costs and short delivery time.

Technologically, to support mass customization process, advanced manufacturing technologies, flexible management techniques, and especially the information technologies are needed. In the Internet plus era, internet service provides a platform for the efficient and spontaneous information interaction, which has been viewed as the essential infrastructure for mass customization. However, due to the communication barriers between consumers and e-retailers, as well as the consumers order and pay for the co-design product that $\mathrm{s} /$ he has never experienced, hence consumers' perceived risks still exist in mass customization process [18]. Therefore, the contributions of our research are: Firstly, highlight collaborative design process, which not only provides the co-design platform among consumer and brand's designer, but also makes possible the instant telecommunication among consumer, brand, and manufacturer; Secondly, explain the enabled technologies for collaborative design, e.g. toolkits for co-design, 3D body scanning, and CAD systems; Thirdly, give some practicable recommendations for apparel mass-customized companies to gain a larger share of market in the Internet Plus era.

\section{Theoretical Background}

\subsection{Apparel Mass Customization}

Initially, Stan Davis (1987) created the term "mass customization" in the book Future Perfect, which became an innovation concept in manufacturing. Later Pine (1993) coined five stages of mass customization with a process continuum, where products range from purely mass produced to completely mass customized (Fig.2). Also he defined mass customization as a hybrid of mass production and craft customization, with rapidness and lower expense. According to Loker (2007), mass customization is a business strategy, focusing on advanced technologies, consumer involvement, and production and distribution. To be Brief, traditional manufacturers have to make changes to meet the needs and requirements for individual consumer without sacrificing the efficiencies or profits [27].
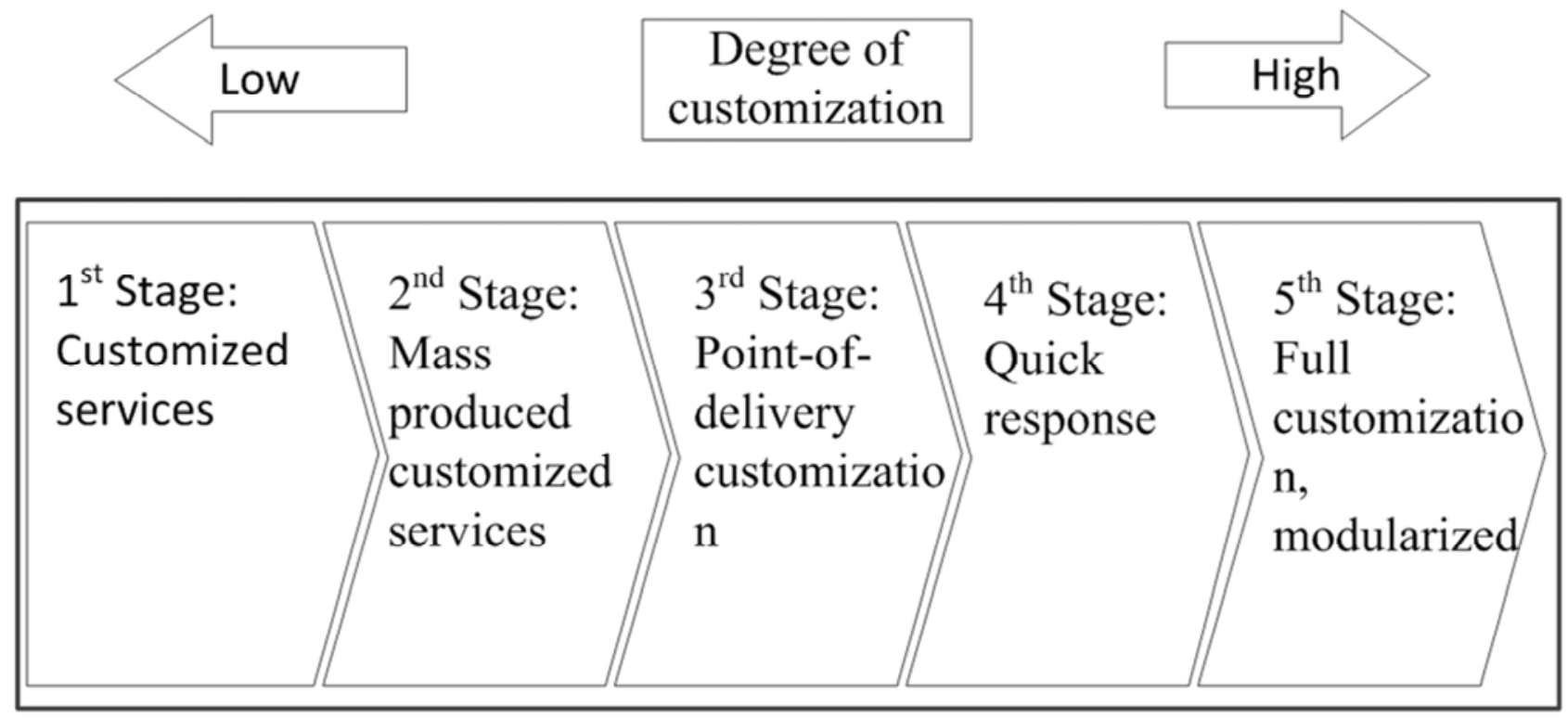

Source: Pine, 1993

Fig. 2. Five stages of mass customization.

When it comes to the fashion industry, focusing on "uniqueness" and "fitness", Piller (2004) has defined mass customization as an innovative development axis. Ashdown (2007) confirmed that the demand for mass-customized garment from individual consumer was steadily growing. In contrast to pure customization strategies, however, which designed to serve products in small niche markets, mass customizers intend to operate in considerably large markets. Yet to implement a mass customization program, the state-of-the-art manufacturing technologies supporting flexible manufacturing systems have to be developed to meet individual design taste as well as fit requirement [16].

The benefits of apparel mass customization are both for consumers and retailers. On one hand, customers achieve a higher level of satisfaction due to the individualized offering and unique shopping experience [35]. On the other hand, mass customization is an efficient way to achieve a wider range of customer needs with lower effort and high flexibility [26]. Further, from the companies' perspective, mass customization provides a more satisfactory purchase experience and facilitates to build long-term relationships with customers [8]. 


\subsection{Co-design Process}

Piller (2005) proclaimed mass customization as, "Customer co-design progress of products and services, which meet the needs of each individual customer with regard to certain product features." Schreier (2006) cited that the 'pride of authorship' effect through consumer co-design process. Likewise, Merle, Chandon, and Roux (2008) defied the customer's experiential co-design value from two dimensions: hedonic and creative achievement. Further, Lee, Damhorst, Campbell, Locker, and Parsons (2011) viewed co-design process as one aspect of mass customization concentrate on design personalized design by offering a high level of interactivity between consumers and retailer. Moreover, Thallmaier (2015), identified customer co-design is a development process, where the customer and provider collectively ideate, elaborate and create a design specification for a product. To summarize, co-design acts as a process of collective creativity, in which ideas and thoughts are shared between at least two people when design a product or service.

While in the field of mass customization, through co-design platform, consumers can actually participate in products development process by selecting different options provided by brands' designers, such as style, fabric, color, monogram, as well as size alternatives [21]. For instance, Magic Manufactory, an app designed by Red Collar, which is one of the most sufficient mass-customized mobile devices for customers, where it provided a wide range of selection for specific product features (e.g. colors, fabrics, and size measurements) to create products that suit individual customers' preferences. Fig. 3 shows mass-customized process of Magic Manufactory.

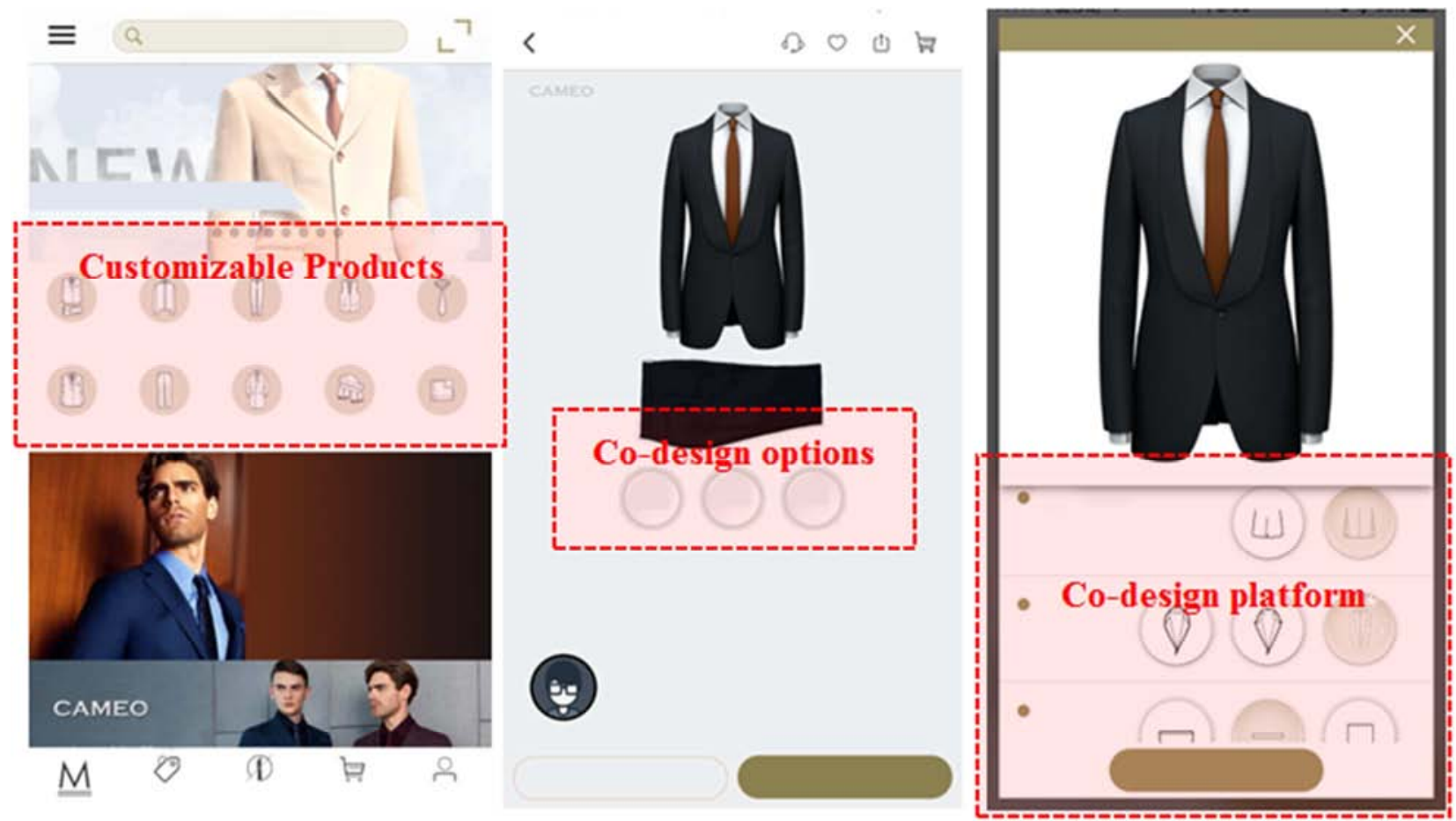

Fig. 3. Mass-customized process of Magic Manufactory.

\subsection{Modular Design}

Modular design has been viewed as a design technique that can be used to develop complex products using similar components [13]. Further, they defined modular design is an attempt to reach both the gains of standardization (high volume normally equals low manufacturing costs) and the gains of customization [28]. Later, Kamrani and Nasr (2010) stated modular design was the process of producing units that perform discrete functions, and then connecting the units together to become a variety of functions. Therefore, the concept of modularity has played a crucial role in the development of the mass customization paradigm. Also the benefits of modular design appear on both sides of the consumers and brands [3]. On one side, product modularity makes the product development process open to individual customer, to enable each customer creates product based on their own preference. On the other side, product modularity allows the firms module the product separately, then the components' variety can be reduced, but offering more diversity of end products. In the apparel mass customization context, modularity enables enterprises to cope with the rapidly changing customer requirements and growing technical complexity. In order to fulfill this strategy, the producer divide garment into different units, such as a tailored-suit and be divided into body, collar, sleeve, pocket, and vent. The brands' designers preform the basic style, and upload the work in modular design database in advances, after that, consumers can choose the standardized components to create personalized products. Then, fig. 4 demonstrates modular design database. 

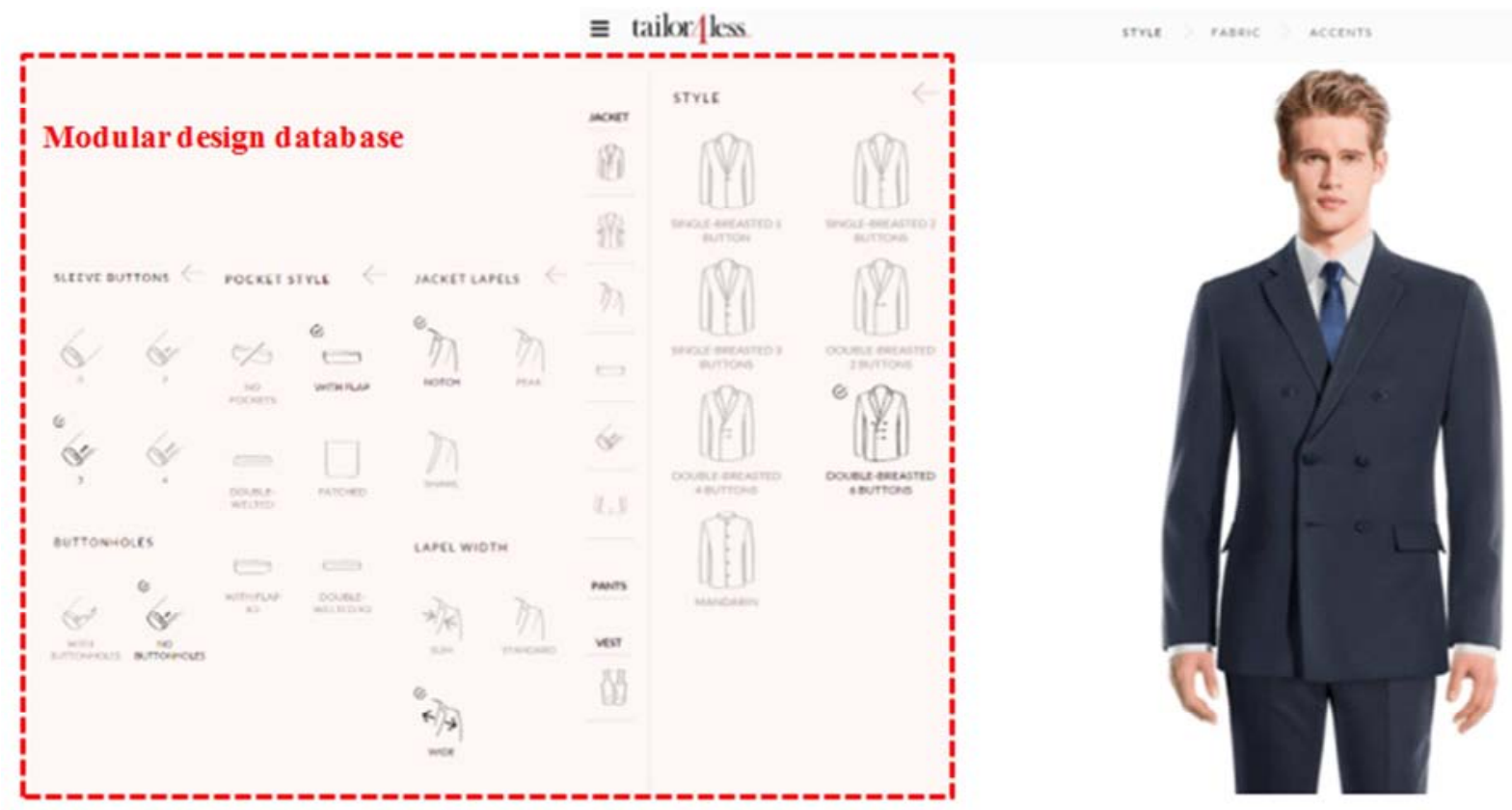

Fig. 4. Demonstrates modular design database.

\section{Enabled Technologies for Collaborative Design}

\subsection{Toolkits for Co-design}

As mentioned, customer co-design act as a unique characteristic of mass customization, enabled by dedicated tools recognized as configurator, modular design database, and co-design interface [7]. These systems are leading the user through the configuration process where diverse alternatives are represented and visualized for customers. Configurators that facilitate the process of gathering customer preferences are considered as the most significant enablers of the mass customization strategy. To be specific, a configurator is implemented at the interface between customers and entrepreneurs via the internet, with the purpose to stimulate customers participate in the product configuration according to their individual requirements [26]. In the Internet Plus era, Internet services are focusing more concentration on the collaboration tools, which enable the user contribute in product development process. Considering the co-design process, consumers are invited to take part in co-creation section by defining, configuring, matching, or modifying an individual preference. Hence, the design configurator brings the potential to respond quickly to customer requirements and generate a range of variant designs to meet individual preference [32].

\subsection{D Body Scanning}

In order to provide fit-based mass-customized apparel products, accurate body measurements are need. Then 3D body scanning is one of the significant technologies that support automatic data gathering in the garment industry.
Commonly, a 3D body scanner is the size of a fitting room, using cameras or lasers to capture over 300,000 data points for each participant's scan within a few seconds. Then the software automatically extracts hundreds of body measurements with high efficacy and accuracy [6]. After that, data can be transferred directly from the scanner to personal computer, which offer precise, accurate, and repeatable data for tailored-garment making. Therefore, 3D body scanning contributes to collect three-dimensional data from individual customers and send them to manufacturers to develop customized-garment.

Currently, 3D body scanning has been viewed as the frontier in solving fit problems. It not only facilitates collecting accurate data, catering to the demand for customized garments, but also builds virtual model fit trials that enhance online clothing shopping experiences. Briefly, it is expected to increase consumer satisfaction and reduce commercial waste due to 'ill-fit' returns. Therefore, 3D body scanning can be regarded as a significant bridge between craftsmanship and computer-aided design technologies, supporting automatic made-to-measure for mass customization strategy.

\subsection{CAD Systems}

Computer-aided design (CAD) systems are considered as the primary tools apply in mass customization, which is to operate garment panel shapes into the digital form [1]. CAD systems are utilized for allowing the modification of patterns for individual body measurement based on body scanning results. Carrere, Istook, Little, Hong, and Plumlee (2001) created a conceptual model that automatically transfers body scanning data to CAD format. The CAD systems can adjust patterns spontaneously according to specific measurement data, without perpetual change from the original garment 
pattern. After that, the CAD file can be directly transferred to automatic cutting machine for pattern cutting.

Apart from the above technologies, other advanced technologies, such as, automatic cutting technology, digital printing, electronic data interchange, and virtual try-on system, are essential in the implementation of apparel mass customization.

\section{Collaborative Design in Internet Plus Era}

\subsection{Collaborative Design}

The Product collaborative development supported by the Internet is a synthesis process, organized by multi-functional collaborative teams, which is aiming to gather and integrate customers' requirements [9]. Furthermore, collaborative design working as an important application of computer technology that telecommunication infrastructure has been established to achieve it. With the help of Internet, collaborative design can effectively support product innovation through the combination of cooperative work and advanced manufacturing technologies, which are significantly different from traditional sequential product development (Fig. 5). Specifically, mass customization establishes a co-operative environment, where the consumers propose individually-designed products and services, the companies provide co-design platform, meanwhile, the manufacturers develop high quality products (Fig. 6).

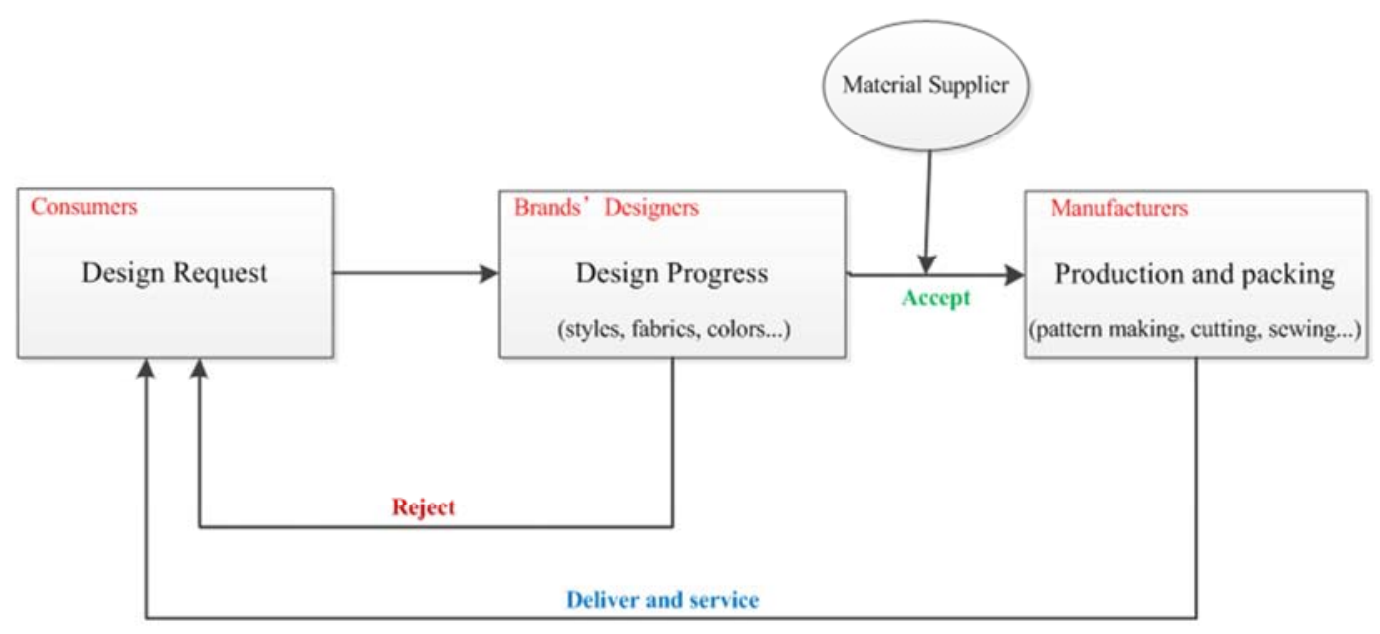

Fig. 5. Traditional sequential product developments.

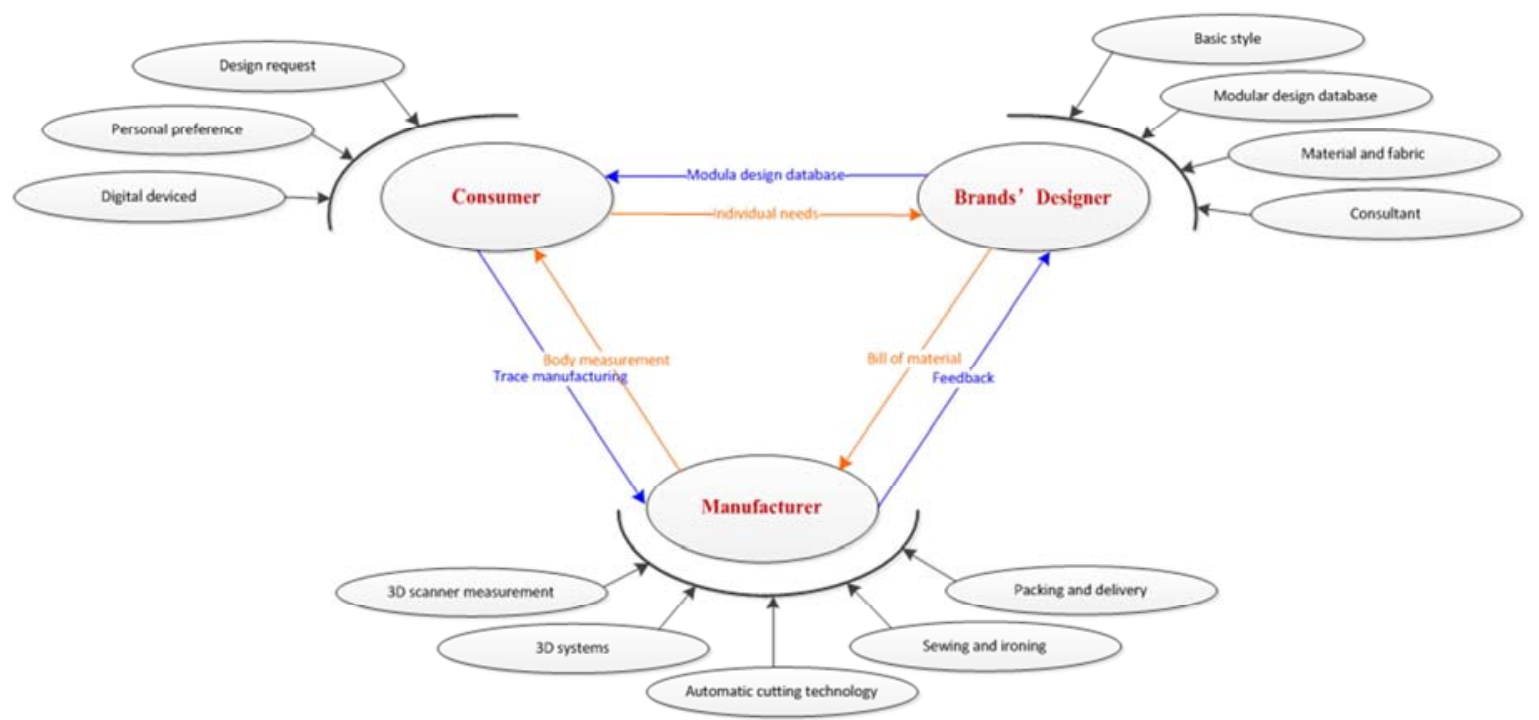

Fig. 6. Collaborative design product developments.

Based on the collaborative design process, it not only enables the consumers to participate in product design stage with the help of brands' designers, also brings the consumers closer to manufacturing of their customized products. As illustrated in Fig. 6, consumers propose their design requests, then the clients design personal product based on their specific needs from modular database. Simultaneously, the brands' designers provide basic design style and modular database, and they have a good selection of suitable material and fabric relate to each garment as well. In addition to that, 
the platform offers an instant communication between consumer and brands' designers to support co-design process. When it comes to the manufacturers, they provide tailored customization technologies, such as 3D body scanner measurement, CAD pattern making, and automatic cutting device. After sewing and ironing, the personal products will be delivered to customers directly. Therefore, the information management and flexible manufacturing technologies make the collaborative design come true in mass-customized process. Compared to traditional sequential product development, as mentioned before, the collaborative design process gives each consumer an opportunity to take part in product design and development process, which used to be the domain of firms.

\subsection{Case Study: Collaborative Design for Apparel Mass Customization}

\subsubsection{Red Collar Group}

Red Collar Group, founded in 1995, specializes in producing customized high-qualified suits series, including suits, pans, shirts, and coats. The company was initially an OEM (original equipment manufacturer) and ODM (original design manufacturer), which has effective assembly line to produce garment for other brands. Due to the fierce competition from the peer manufactures, Red Collar Group has been focusing on high-end men's suit customization MTM (made-to-order) business since 2005, and becomes an active explorer in Chinese garment industry [12]. By the end of 2012, Red Collar achieved more than $150 \%$ year-on-year growth among production, sales and profit targets [11].
Currently, Red Collar has grown into a mega C2M (customer to manufactory) digital ecosystem with advanced technologies in garment manufacturing industry, and continued to introduce $3 \mathrm{D}$ printing, big data and other new technologies.

With the help of Internet services, Red Collar established accessible collaborative design platform-KUTE Internet Platform to meet individual customer requirements, and build a seven-day personalized product development process to support MTM strategy (Fig. 7). First of all, a giant version of database is the key to achieve MTM business mode. Thanks to its OEM and ODM background, Red Collar develops a huge database with more than one billion body type version for basic pattern making. At the same time, brand's designers create abundant design database, including styles, colors, fabrics, and other materials, to enable individual consumer make personal garment with less effort. After that, advanced manufacturing technologies help achieve real-time monitoring among consumers, brands, and manufactures. Once the consumers submit product orders under any circumstances, then firms instantly analyze the design requirements (such as fabrics, lining, trimming, et al.) to develop production schedule based on retailers' current inventory. Besides, well-organized CAD systems facilitate transform product information into digital manufacturing automatically. After the whole process of pattern making, cutting, sewing, ironing, testing and packaging, the customized garment will be delivered to the product owner via flexible logistics.

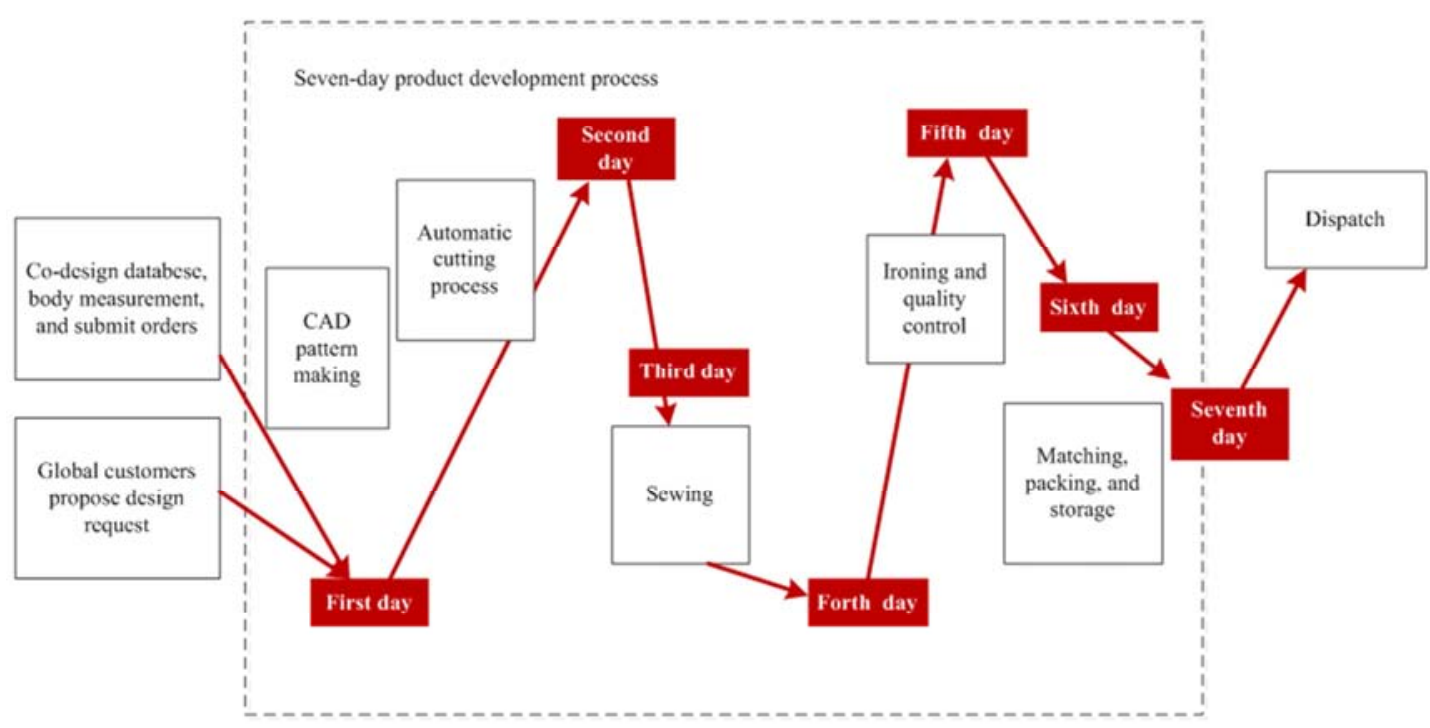

Source: Red Collar Official website

Fig. 7. A seven-day mass-customized product development.

\subsubsection{Saint Angelo}

Zhejiang Saint Angelo Clothing co., LTD, founded in June 2001, mainly engaged in design and product suit, shirt, and other lines of menswear. In recent years, the company has three clothing manufacturing bases of Wenzhou, Shanghai and Anhui, and it has more than 1,500 retail terminal networks, 7 thousand employees, over 4 billion RMB total assets, and more than 3 billion RMB of annual output value [37]. In the year of 2015, Saint Angelo started to launch the $\mathrm{C} 2 \mathrm{~B}$ (consumer to business) full-line private custom business 
with tailored technique, to fellow the trend of mass customization in Internet Plus era. The company has invested more than one hundred million RMB to reform the intelligent assembly line to make production plans on the basis of sales and align production seamlessly, aiming to preempt the high-end personalization business market.

The smart cloud-wing system that coined by Saint Angelo, consists of one body and two wings, which provide a collaborative design platform among clients, brands, and manufacturers. To be specific, the transparent cloud factory of smart manufacturing is viewed as the main body, while the exclusive customization cloud platform and data sharing platform are taken as the two wings. Through the smart cloud-wing system, making the $\mathrm{C} 2 \mathrm{M}+\mathrm{O} 2 \mathrm{O}$ (online to offline) integrated industrial and trade service management mode become reality. Saint Angelo takes the consumers' demands as the starting point, then creates an EMTM (electronic made to measure) virtual customization mode suitable for large-scale personalized customization. As illustrated in Fig. 8. At the same time, it develops a web-interface on ecommerce, allowing the consumers input their personalized requirements by selecting produce features (e.g. fabrics, styles, techniques, yarn colors) from modular design database, to create their exclusive customized garments. Based on the intelligent assembly line, advanced CAD systems can form into independent pattern model "one man, one version" and generate customization order automatically. Also, the systems realize the traceable digital management along the whole process of smart manufacturing.

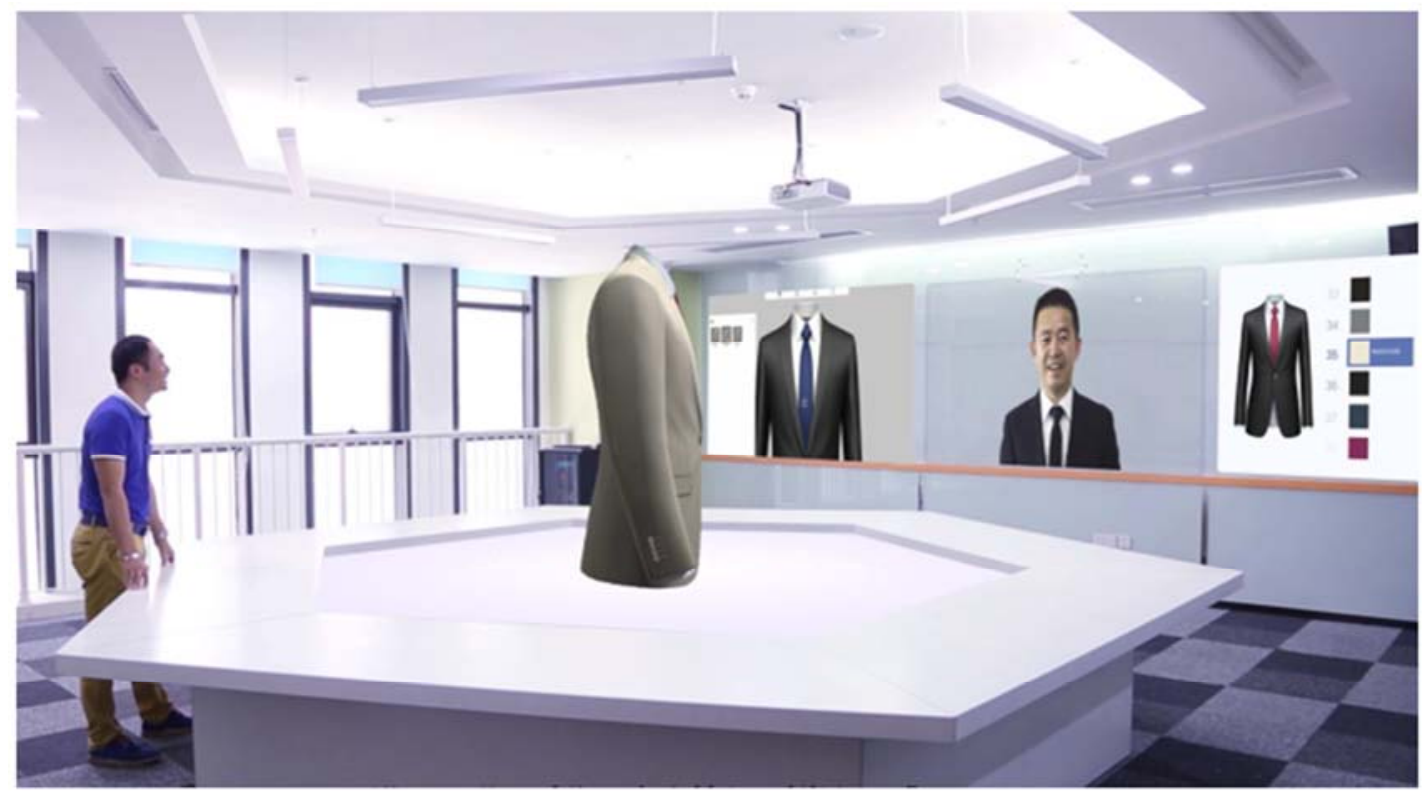

Source: Red Collar Official website

Fig. 8. EMTM collaborative design platform.

As a result, with the help of smart cloud-wing system, the production efficiency increase by $50 \%$, the product qualification ratio rise up to $99 \%$, while the number of personnel is cut by $10 \%$. Moreover, the product delivery time is shortened to 7 days from 15 days. Ultimately, through the smart cloud-wing platform, the mission of Saint Angelo is to build an internet + industrial ecosystem that can accumulate and integrate big data from the whole apparel industry, promoting the upstream and downstream interconnectivity, sharing and coordination of the industry chain, further to develop an information sharing platform related to design, technique, product among customers, brands, and manufacturers.

\section{Recommendations and Conclusion}

According to Pine and Gilmore (1999) asserted that our society has been moving into an era of an experience economy. The role of the consumer changes into a co-designer or co-developer of the products. As mentioned above, collaborative design allows multi-designer from different locations to participate in the same design process, which plays a core role in mass customization action. Specifically, with the help of sophisticated Internet-based service systems, collaborative design method enables the firms to provide customized products and services based on the needs and requirements of individual customers. Also collaborative design method transformed the masses of data into meaningful and understandable information, to provide a quick and effective interaction among customers, companies, and manufacturers via the Internet.

Therefore, through our study, we give three recommendations for mass customization strategy in apparel industry:

1. Considering consumer co-design process determines the success of mass customization, the interface for co-design process should be well-organized and simplified, otherwise it may lead to consumers' mass 
confusion, then reduce consumer satisfaction, and even decrease users purchase intension.

2. In the era of Internet Plus, mobile internet plays an increasing significant role in the apparel industry. Hence, it is a wise choice for the entrepreneurs to develop aesthetic, clear, and understandable applications on digital media for e-commerce.

3. Privacy risk has to be taken into account in Internet Plus era. As customer's personal information have been collected by companies during the customized process, entrepreneurs should take the responsibility to store and make appropriate use of personal information.

\section{Acknowledgements}

The authors would like to appreciate the Chinese Central Communist special funds for basic research projects in Donghua University (NO. 16D110715), which is focusing on the research and application of Fashion trend from the uniform perspective.

\section{References}

[1] Ashdown, S. P., Sizing in Clothing: Developing Effective Sizing Systems for Ready-To-Wear Clothing, Woodhead Publishing Limited, Cambridge, England, 2007.

[2] Ashdown, S. P. and Loker S., Mass customized target market sizing: Extending the sizing paradigm for improved apparel fit, Design Practice, 2010, pp. 147-173.

[3] Blecker T., Friedrich G., Kaluza B., Abdelkafi N., and Kreutler G., Product Modularity in Mass Customization, Information and Management Systems for Product Customization, Vol. 7, pp. 163-179.

[4] Carrere, C., Istook, C., Little, H., Hong, T., Plumlee, T., Automated Garment Development from Body Scan Data, National Textile Centre Annual Report, National Textile Centre, Auburn, AL, 2001.

[5] Davis, S. M., Future Perfect, Adison-Wesley, 1987, 5 (5): 80 87.

[6] Faust M. E. and Carrier S., 3D Body Scanning's Contribution to the Use of Apparel as an Identity Construction Tool, Digital Human Modeling, 2009, LNCS 5620, pp. 19-28.

[7] Franke N, Piller F., Value creation by toolkits of user design and innovation: the watch case, Journal of Product Innovation Management, 2004, 21 (6), pp. 401-415.

[8] Fiore A. M., Lee S. E., and Kunz G., Individual differences, motivations, and willingness to use mass customization options, Journal of Fashion Marketing and Management, 2004, Vol. 5(2), pp.99-107.

[9] Gao Q., Du Z., and Qu Y., Analysis on Engineering Change Management Based on Information Systems, Global Design to Gain a Competitive Edge, 2008, pp. 283-291.

[10] He B., Wang Y., Song W., and Tang W., Design resource management for virtual prototyping in product collaborative design, Journal of Engineering Manufacture, 2015, Vol. 229 (12), pp. 2284-2300
[11] Hu H., Huang T., Zeng Q., and Zhang S., The role of institutional entrepreneurship in building digital ecosystem: A case study of Red Collar Group (RCG), International Journal of Information Management, 2016, Vol. 36, pp. 496-499.

[12] Jia G., Wang J., Zhang R. Zong H., and Yao J., Red Collar Group in Qingdao-High-End Clothing Customization Service, Manufacturing Servitization in the Asia-Pacific, 2016, pp. 289-315.

[13] Kamrani A. K. and Salhieh S. M., Modular Design, Product Design for Modularity, 2002, pp. 45-84.

[14] Kamrani A. K. and Nasr E. A., Modular Design, Engineering Design and Rapid Prototyping, 2010, pp. 57-86.

[15] Kim W. M. and Lee K. P., Collaborative product design processes of industrial design and engineering design in consumer product companies, Design Studies, 2016, Vol 46, pp 226-260.

[16] Lee S., Kunz G., Fiore A. M., and Campbell J. R., Acceptance of mass customization of apparel: merchandising issues associated with preference for product, process, and place. Clothing and Textiles Research Journal, 2002, 20, pp. 138-146.

[17] Lee H. H., Damhorst M. L., Campbell J. R., Locker S., and Parsons J. L., Consumer Satisfaction with A Mass Customized Internet Apparel Shopping Site. International Journal of Consumer Studies, 2011, pp. 316-329.

[18] Lee H. H. and Moon H., Perceived Risk of Online Apparel Mass Customization: Scale Development and Validation, Clothing and Textiles Research Journal, 2015, Vol. 33 (2), pp. $115-128$.

[19] Loker S., Mass Customization and sizing, Sizing in clothing, Cambridge, 2007, pp. 246-263.

[20] Merle A., Chandon J. L., and Roux E., Understanding the perceived value of mass customization: the distinction between product value and experiential value, Research of Applications and Marketing, 2008, vol. 23, pp. 27-50.

[21] Piller, F. T., Mass Customization: Reflections on the State of the Concept, International Journal of Flexible Manufacturing Systems, 2004, Vol. 16, No. 4, pp. 313-334.

[22] Piller, F. T., Mass Customization, Impact on International Manufacturing, Presentation at the Mass Customization: Key to Competitiveness for Textiles-based Industries, Ypsilanti, Michigan 2005, May 19-20.

[23] Piller F. T., Observations on the present and future of mass customization, International Journal of Flexibility Manufacturing System, 2007, 19: 630-636.

[24] Pine, B. J. II, Mass Customizing Products and Services, Planning Review, 1993, Vol. 21, No. 4, pp. 6-14.

[25] Pine II, B. Joseph and Gilmore, James H., The Experience Economy, Boston, Massachusetts: Harvard Business School, 1999.

[26] Pistova P. R. A. T., Web-based Product Configuration for Mass Customization, School of Engineering in Jönköping in the subject area Production Systems, 2011.

[27] Satam D., Liu Y., and Lee H. J., Intelligent design systems for apparel mass customization, the Journal of the Textile Institute, 2011, Vol. 102, No. 4, pp. 353-365. 
[28] Salhieh S. M. and Kamrani A. K., Modular Design, Collaborative Engineering: Theory and Practice, 2007, pp. 207-226.

[29] Schreier M., The value increment of mass-customized products: an empirical assessment, Journal of Consumer Behaviour, Vol. 5, pp. 317-327.

[30] Thallmaier S. R., Customer Co-Design, A Study in the Mass Customization Industry, Leipzig Graduate School of Management, 2014.

[31] The Internet Plus Action Plan, government work report, China's State Council, 2015.

[32] Verhagen, W. J. C., Bermell-Garcia, P., van Dijk, R. E. C., Curran, R.: A critical review of knowledge-based engineering: an identification of research challenges. Adv. Eng. 2012, Inform. 26, pp. 5-15.
[33] Wang Z., Chen C., Guo B., Yu Z., and Zhou X., Internet Plus in China, IEEE Computer Society, 2016, pp. 5-8.

[34] Wang W., Liu S., and Zhang Y., User experience design in internet plus era, 5th International Conference, 2016, pp. 172-183.

[35] Yeung H. T., Choi T. M., and Chiu C. H., Innovative Mass Customization in the Fashion.

[36] Industry, International Handbooks on Information Systems, 2010, DOI 10, pp. 423-454.

[37] http://www.baoxiniao.com.cn/.

[38] http://www.redcollar.com.cn/. 